\title{
Application of tuned vibration absorbers in fluid mounts
}

\author{
Mohammad Jalali Mashayekhi and Nader Vahdati* \\ School of Mechanical and Aerospace Engineering, Nanyang Technological University, 50 Nanyang Avenue, \\ 639798, Singapore
}

Received 13 February 2008

Revised 21 November 2008

\begin{abstract}
The need to reduce the fuel consumption of vehicles leads to having lighter chassis' with lighter engines yet maintaining engine power. These new design requirements are in contrast with the vibration isolation requirements. To keep the vehicles light yet provide good cabin noise and vibration isolation, requires a new vibration isolation technology. Fluid mounts have been used in the aerospace and the automotive industry to provide cabin noise and vibration reduction for years. With the use of passive fluid mounts, the highest cabin noise and vibration reduction is achieved at a frequency called "Notch Frequency". But typical passive fluid mounts have only one notch frequency. So the best cabin noise and vibration reduction is only achievable at one frequency. In this paper, a new fluid mount design in combination with a tuned vibration absorber is proposed. Bond graph modelling technique is used to model the new fluid mount design. The physical model and simulation results are presented. The effect of the natural frequency of the TVA on the dynamic stiffness of the fluid mount is studied.
\end{abstract}

Keywords: Fluid mount, tuned vibration absorber

\section{Introduction}

Vibration isolation is an important issue in the automotive and the aerospace industry. Automotive companies compete to design more comfortable vehicles with lower cabin noise and vibration. Additionally, fuel consumption reduction is another important criterion in designing the new vehicles. In order to reduce fuel consumption, the weight of the vehicle is kept as low as possible [1]. But a lighter and therefore more flexible chassis with a more power-intensive vehicle engine tend to deteriorate the vibration isolation properties of the vehicle's cabin [2].

Usually, the car engine or airplane engine is connected to the chassis or the fuselage via three to four engine mounts. Engine mounts have two major tasks. The first task is to connect the engine to the chassis or the fuselage and the second task is to prevent the transmission of the engine induced vibrations to the cabin.

There are many different types of engine mounts on the market that have been used in the past to isolate the cabin from the engine noise and vibrations and they are hard mounts, elastomeric mounts, wire mesh mounts, and passive fluid mounts.

Passive fluid mounts have been used in the automotive and the aerospace industry to provide cabin noise and vibration isolation since 1940's. There are two types of fluid mount designs that are often used in the industry: the single pumper [3] and the double pumper [4]. The focus of this paper will be on the single pumper fluid mounts.

In this paper a passive single pumper fluid mount is combined with a passive tuned vibration absorber (TVA) to develop a multiple notch fluid mount device. The design, mathematical models, and simulation results of this new design are presented.

\footnotetext{
*Corresponding author. Tel.: +65 6790 4332; Fax: +65 6791 1859; E-mail: mnader@ntu.edu.sg.
} 


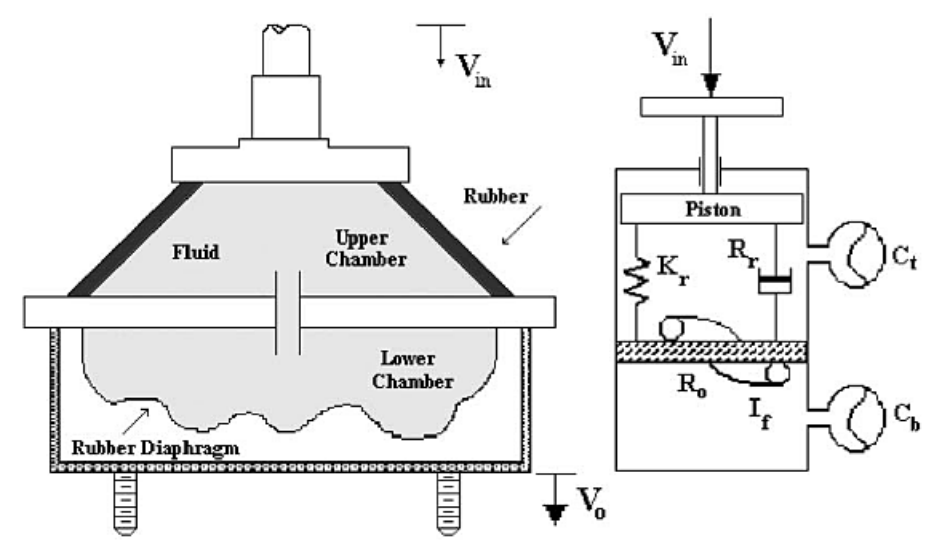

Fig. 1. A typical passive single-pumper fluid mount and its physical model [5].

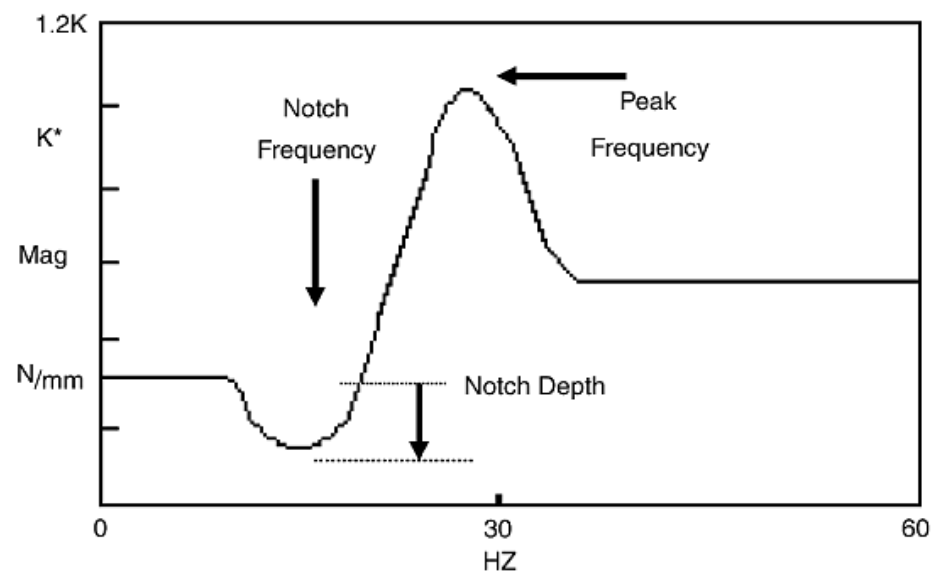

Fig. 2. Typical dynamic stiffness of a fluid mount versus frequency [5].

\section{Passive fluid mounts}

A typical passive single-pumper fluid mount consists of two chambers that are connected to each other through a tube or a hose called "inertia track". The two chambers are filled with an incompressible fluid. Figure 1 shows the configuration of a typical passive single-pumper fluid mount. As the fluid mount is subjected to a sinusoidal displacement, the fluid will oscillate between the two fluid chambers (upper and lower chambers). At some specific frequency, the fluid goes to resonance. This frequency is coined "notch frequency" [2,4,5].

The dynamic stiffness of fluid mounts is strongly frequency dependent. Figure 2 shows a typical dynamic stiffness $\left(\mathrm{F}_{i n} / \mathrm{X}_{i n}\right)$ of a passive fluid mount versus frequency. Notice that the dynamic stiffness of a fluid mount gets its minimum value at the "notch frequency". It is at this frequency that the best cabin noise and vibration isolation is achieved.

Usually fluid mounts are designed such that their notch frequency coincides with the frequency of the longest period of constant speed of the vehicle or the aircraft. For example, in the case of an aircraft, the fluid mount notch frequency is usually designed such that it coincides with the frequency of the cruise speed. Otherwise, vibration isolation would not be optimum [5]. But at the cruise speed, there are multiple engine disturbance inputs of different amplitudes and frequencies. But since a passive fluid mount design has only one notch, the notch can only be designed to coincide with only one of the disturbance inputs and therefore other disturbance inputs are transmitted to the cabin. 


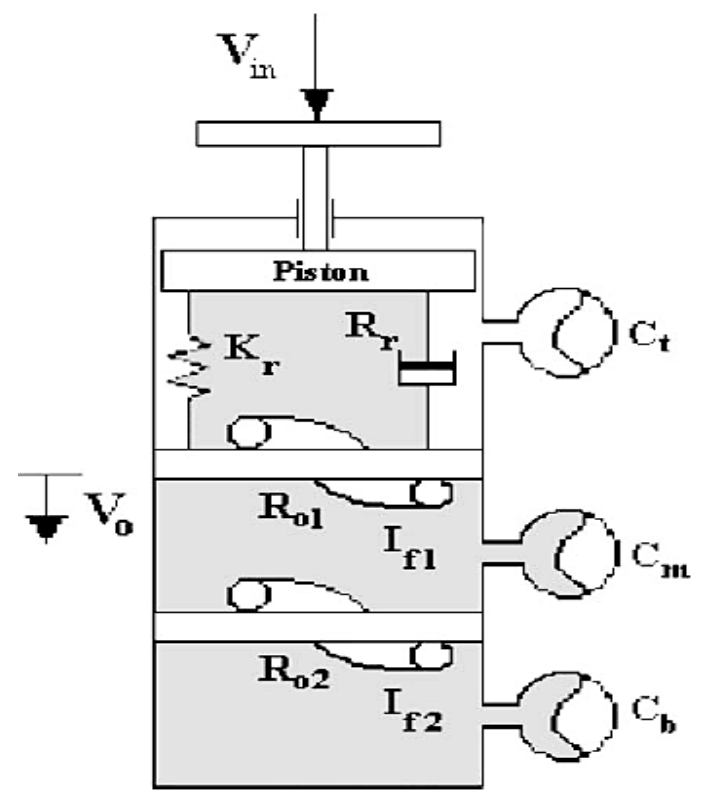

Fig. 3. Physical model of the double notch fluid mount [5].

So, it is highly desirable to have more than one notch frequency. For example, in the case of the aerospace applications, if the fluid mount could have two notches, one of them could be tuned to coincide with the N1 frequency (engine low speed shaft imbalance frequency) and the other to coincide with the N2 frequency (engine high speed shaft imbalance frequency) and the cabin noise and vibration isolation would be more effective.

A Literature survey was conducted to find out if there is any double or multiple notch fluid mount design documented. Reference [5] has introduced a design for a double notch fluid mount as shown in Fig. 3. With the design of Fig. 3, the mount will have one more notch frequency which is desirable, but the location of the new notch is not easily tunable, particularly once the mount is manufactured. In the design of Fig. 3, re-tuning of the notch frequencies requires re-machining of the inertia tracks, or change in the rubber modulus, which is very costly.

In general, placing the notch frequency at the right location is not easy. Due to manufacturing tolerances, the notch frequency usually does not coincide with the desired value in the first manufacturing pass and as a result fluid mounts need to be redesigned and re-tuned several times. This procedure is time consuming and costly. Some researchers have proposed design methods to avoid this expensive trial and error procedure [6,7] but most of these methods normally involve experimental data for optimization which is again not desirable.

Here in this paper, we are introducing a new single pumper fluid mount design that will have two notches and the new notch is easily tunable using a TVA and the new notch can be placed at any desired frequency without any major redesign of the fluid mount.

\section{The new fluid mount design}

In reference [8], a new fluid mount design concept was introduced where the lower chamber soft rubber diaphragm of Fig. 1 was replaced by a piston, a spring, and a damper. The piston/spring system acts like the rubber diaphragm and as a fluid accumulator. Here in this paper, the same design is used but a TVA is added to the piston as shown in Fig. 4. The piston will be covered with a fabric diaphragm (not shown) to minimize fluid leakage from the bottom fluid chamber to the air chamber. A fabric diaphragm is different than a rubber diaphragm in a sense that it seals the bottom chamber, allows the piston motion, and yet does not impact the volumetric stiffness of the bottom chamber. The spring, below the piston, can be a metal spring or a rubber spring. In either case, the metal or the rubber spring will have some hysteretic damping, so here in this paper, it is assumed that the spring acts like a spring and a viscous damper. 


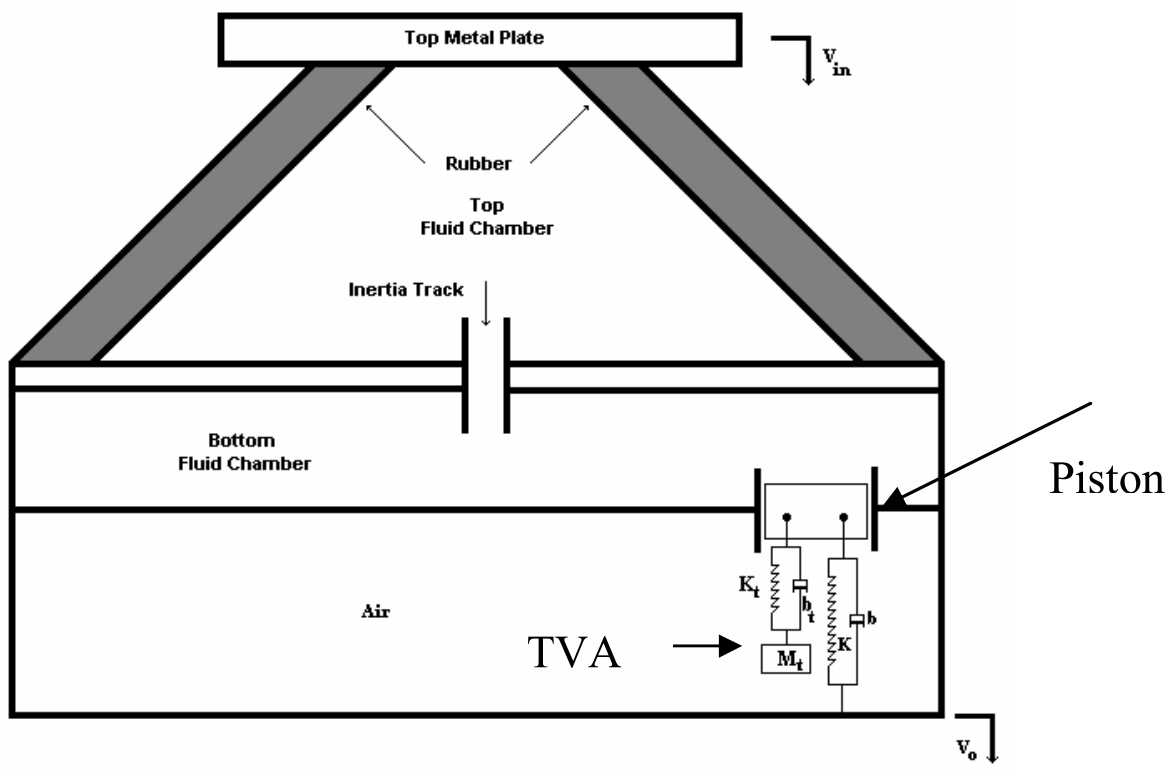

Fig. 4. New fluid mount design.

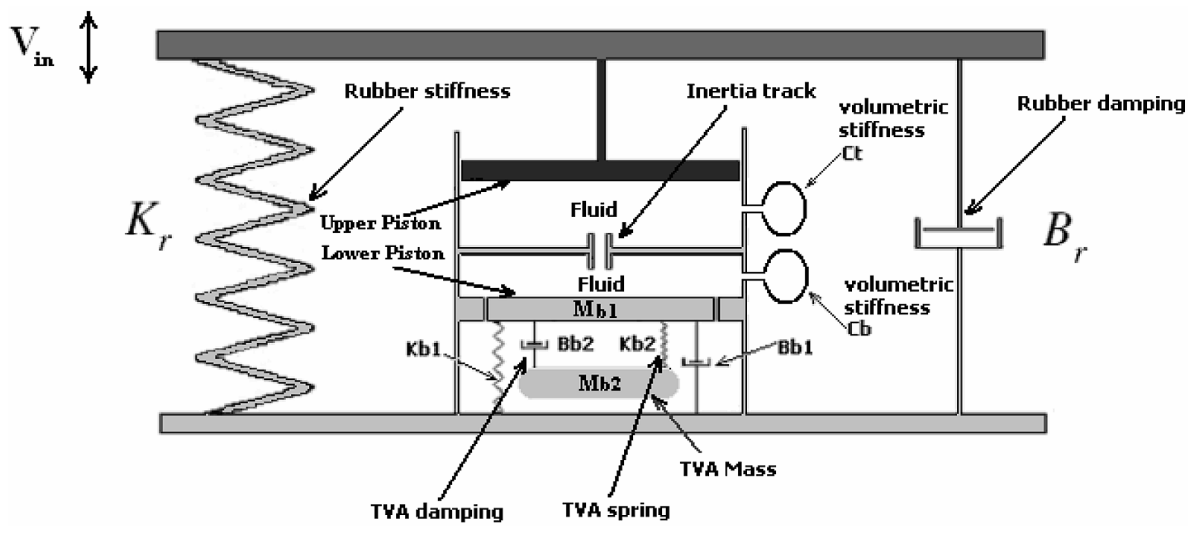

Fig. 5. Physical model of a fluid mount plus a TVA.

\subsection{Physical and bond graph model of the fluid mount with the TVA}

In order to represent the physical model of the new fluid mount design, it is needed to deal with two different energy domains: namely mechanical and hydraulic energy domains. Bond graph modeling technique [9] enables us to deal with multi energy domains very efficiently. This method has been employed to model the fluid mount plus the TVA design.

In order to find the bond graph model of Fig. 4, the first step is to create the physical model of Fig. 4. The mathematical model developed from the physical model should be simple enough to be solved and yet should accurately keep the main characteristics of the real system. The simplified physical model of the fluid mount with the TVA of Fig. 4 is represented in Fig. 5. The bond graph model of Fig. 5 is shown in Fig. 6.

\subsection{Modeling assumptions}

In companies that manufacture fluid mounts, great efforts are made to reduce rubber damping, inertia track flow losses, and friction in order to deepen the notch. If damping is not reduced, no notch frequency will appear. So here 


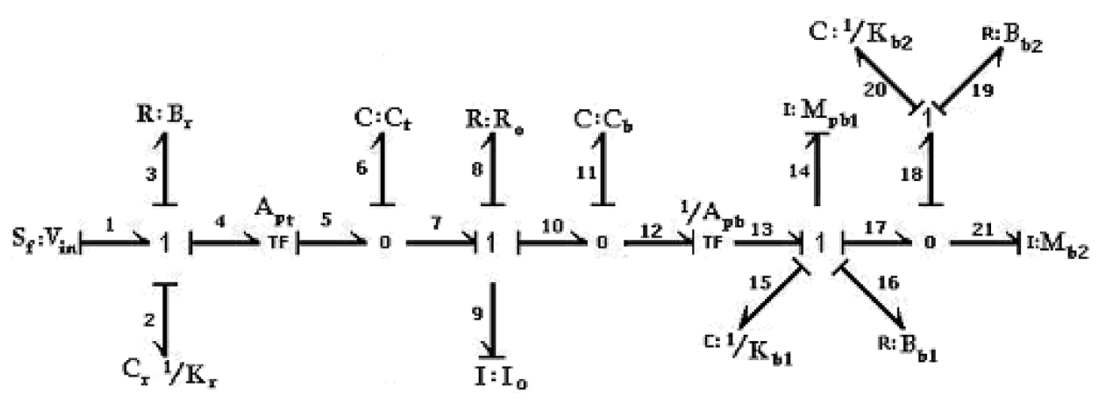

Fig. 6. Bond graph model of Fig. 5.

in this paper, it is assumed that all losses and friction will be minimized to ensure a descent notch depth. Knowing this, the following modeling assumptions are made.

In the model of Figs 5 and 6, the damping of the upper chamber in the bulge direction is assumed to be small and negligible. The friction between the piston and the fluid mount housing is assumed small and negligible. The pressure drop, $\Delta P$, across the inertia track is assumed to have a linear relationship with the flow rate, $\mathrm{Q}$, meaning $(\Delta P=R Q)$, and the inertia track is designed such that flow losses are small.

\subsection{State space equations}

State space equations derived from the bond graph model of Fig. 6 are shown in Eq. (1a-h). In the state space equations, $\mathrm{q}_{2}, \mathrm{q}_{6}, \mathrm{q}_{11}, \mathrm{q}_{15}$, and $\mathrm{q}_{20}$, are the generalized displacement variables, and $\mathrm{p}_{9}, \mathrm{p}_{14}$, and $\mathrm{p}_{21}$ are the momentum variables. The states are defined as follows:

$\mathrm{q}_{2}$ Relative displacement across the spring $\mathrm{K}_{r}$

$\mathrm{q}_{6}$ Volume change in the top fluid chamber

$\mathrm{q}_{11}$ Volume change in the bottom fluid chamber

$\mathrm{q}_{15}$ Relative displacement across the spring $\mathrm{K}_{b 1}$

$\mathrm{q}_{20}$ Relative displacement across the TVA (across the spring $K_{b 2}$ )

$\mathrm{p}_{9}$ Inertia track fluid momentum

$\mathrm{p}_{14}$ Bottom fluid chamber piston momentum (momentum of the mass $\mathbf{M}_{b 1}$ )

$\mathrm{p}_{21}$ TVA mass momentum (momentum of the mass $\mathbf{M}_{b 2}$ )

\subsubsection{State space equations}

$$
\begin{aligned}
\dot{q}_{2} & =V_{i n} \\
\dot{q}_{6} & =A_{p t} V_{i n}-\frac{p_{9}}{I_{o}} \\
\dot{p}_{9} & =\frac{q_{6}}{C_{t}}-R_{f} \frac{p_{9}}{I_{f}}-\frac{q_{11}}{C_{b}} \\
\dot{q}_{11} & =\frac{p_{9}}{I_{f}}-A_{p b} \frac{p_{14}}{M_{p b 1}} \\
\dot{p}_{14} & =A_{p b} \frac{q_{11}}{C_{b}}-K_{b 1} q_{15}-B_{b 1} \frac{p_{14}}{M_{p b 1}}-\left[B_{b 2}\left[\frac{p_{14}}{M_{p b 1}}-\frac{p_{21}}{M_{p b 2}}\right]+K_{b 2} q_{20}\right] \\
\dot{q}_{15} & =\frac{p_{14}}{M_{p b 1}} \\
\dot{q}_{20} & =\frac{p_{14}}{M_{p b 1}}-\frac{p_{21}}{M_{p b 2}} \\
\dot{p}_{21} & =B_{b 2}\left[\frac{p_{14}}{M_{p b 1}}-\frac{p_{21}}{M_{p b 2}}\right]+K_{b 2} q_{20}
\end{aligned}
$$


Table 1

Baseline parameters for the fluid mount plus TVA

\begin{tabular}{clcc}
\hline Symbol & Description & Value & Dimension \\
\hline$A_{p t}$ & Piston area & $9 e-3$ & $\mathrm{~m}^{2}$ \\
$K_{r}$ & Rubber stiffness & $2.05 e 6$ & $\mathrm{~N} / \mathrm{m}$ \\
Tan $\delta$ & For low damped mid range elastomers, G'/G' & 0.04 & Dimensionless \\
Tan $\delta$ & For low damped low shear modulus elastomers, G'/G' & 0.02 & Dimensionless \\
$B_{r}$ & Hysteresis damping of rubber & 522.0 & $\mathrm{N.s} / \mathrm{m}$ \\
$C_{t}$ & Top chamber rubber volumetric compliance & $1 / 1.1 e 11$ & $\mathrm{~m}^{5} / \mathrm{N}$ \\
$C_{b}$ & Bottom chamber fluid volumetric compliance & $1 / 2.1 e 14$ & $\mathrm{~m}^{5} / \mathrm{N}$ \\
$R_{f}$ & Fluid flow resistance of the inertia track & $6.4 e 6$ & $\mathrm{N.s} / \mathrm{m}^{5}$ \\
$K_{b 1}$ & Stiffness of the spring $K_{b 1}$ & 876 & $\mathrm{~N} / \mathrm{m}$ \\
$B_{b 1}$ & Equivalent hysteresis damping of the spring & 0.11 & $\mathrm{N.s} / \mathrm{m}$ \\
$A_{p b}$ & Piston area for the bottom chamber & $6.45 e-4$ & $\mathrm{~m}$ \\
$M_{p b 1}$ & Bottom chamber piston mass & 45.3 & $\mathrm{grams}$ \\
$M_{p b 2}$ & TVA mass & 100 & $\mathrm{grams}$ \\
$K_{b 2}$ & TVA stiffness (Variable during simulation) & 876 & $\mathrm{~N} / \mathrm{m}$ \\
$B_{b 2}$ & TVA equivalent hysteresis damping & 0.186 & $\mathrm{N.s} / \mathrm{m}$ \\
$\rho$ & Fluid density & 1770 & $\mathrm{Kg} / \mathrm{m}^{3}$ \\
$L_{t}$ & Inertia track length & 0.177 & $\mathrm{~m}$ \\
$d_{t}$ & Inertia track diameter & 0.0216 & $\mathrm{~m}$ \\
$X_{m}$ & Maximum input displacement & \pm 0.0381 & $\mathrm{~mm}$ \\
& & \pm 1.5 & $\mathrm{mils}$ \\
\hline
\end{tabular}

The transmitted force, the effort at bond 1 , is equal to:

$$
F_{i n}=K_{r} q_{2}+B_{r} V_{i n}+A_{p t} \frac{q_{6}}{C_{t}}
$$

Dynamic stiffness $\left(\mathrm{F}_{i n} / \mathrm{X}_{i n}\right)$ of this system can be obtained by the use of Laplace transformation and is shown below:

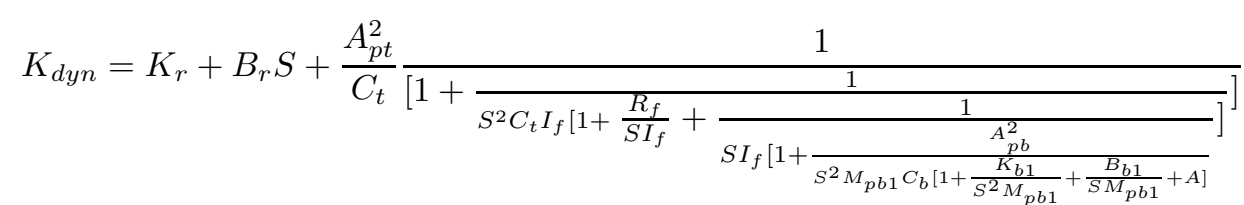

Where the parameter $\mathrm{A}$ is equal to:

$$
A=\frac{B_{b 2}\left[\frac{B_{b 2}}{S M_{p b 1}}+\frac{K_{b 2}}{S M_{p b 1}}\right]}{S M_{p b 2}\left[1+\frac{B_{b 2}}{S M_{p b 2}}+\frac{K_{b 2}}{S M_{p b 2}}\right]}+\frac{K_{b 2}}{S^{2} M_{p b 1}}-\frac{K_{b 2}\left[\frac{B_{b 2}}{S M_{p b 1}}+\frac{K_{b 2}}{S M_{p b 1}}\right]}{S^{2} M_{p b 1}\left[1+\frac{B_{b 2}}{S M_{p b 2}}+\frac{K_{b 2}}{S M_{p b 2}}\right]}
$$

It is important to mention that Eq. (3a) should be reduced to the dynamic stiffness equation of a fluid mount without a TVA if $M_{p b 2} \rightarrow 0$. It is the limit case of this equation and can be used to check its correctness. By finding the limit of $K_{d y n}$ when $M_{p b 2} \rightarrow 0$, the dynamic stiffness, Eq. (3a), approaches:

$$
K_{d y n}=K_{r}+B_{r} S+\frac{A_{p t}^{2}}{C_{t}} \frac{S^{2}+S \frac{R_{f}}{I_{f}}+\frac{K_{b}}{I_{f}}}{S^{2}+S \frac{R_{f}}{I_{f}}+\frac{1 / C_{b}+1 / C_{t}}{I_{f}}}
$$

This expression is exactly the same dynamic stiffness of a classical passive single pumper fluid mount. To do MATLAB simulations, it is needed to assume some baseline values for all of the fluid mount parameters. The baseline fluid mount parameters are defined in Table 1 . The fluid inertia of the inertia track $\left(I_{f}\right)$ can be calculated as follows.

$$
I_{f}=\frac{\rho L_{t}}{A_{t}}=\frac{4 \rho L_{t}}{\pi d_{t}^{2}}
$$




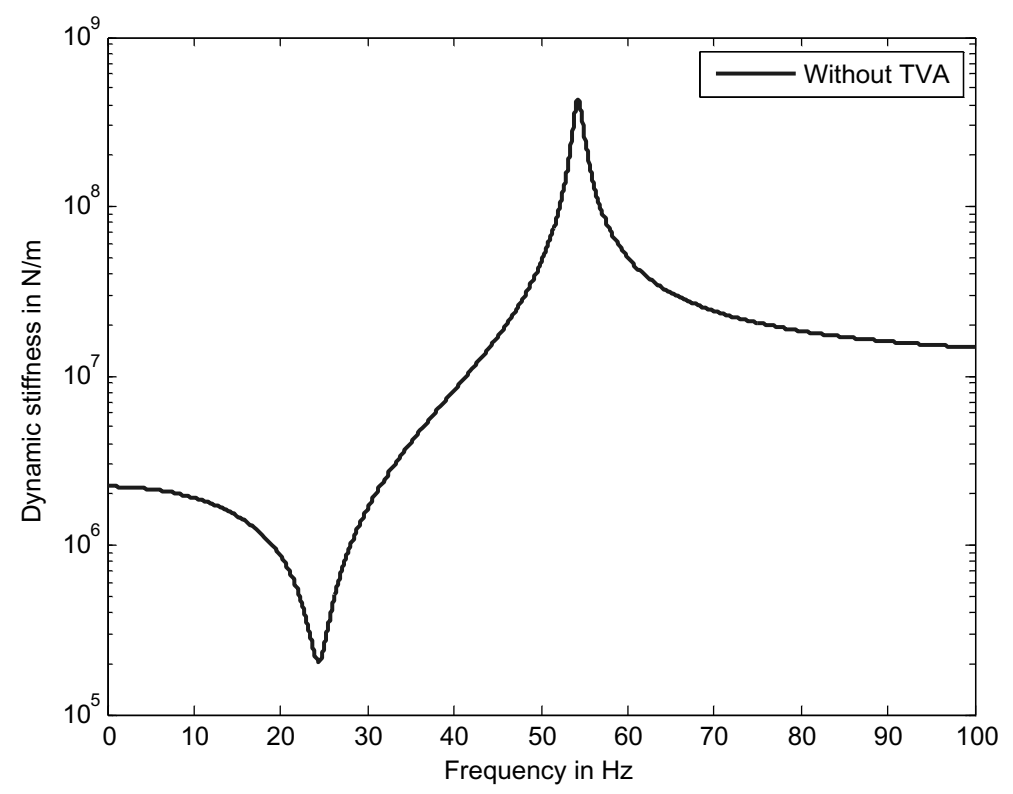

Fig. 7. Dynamic stiffness of a typical fluid mount - semi log plot.

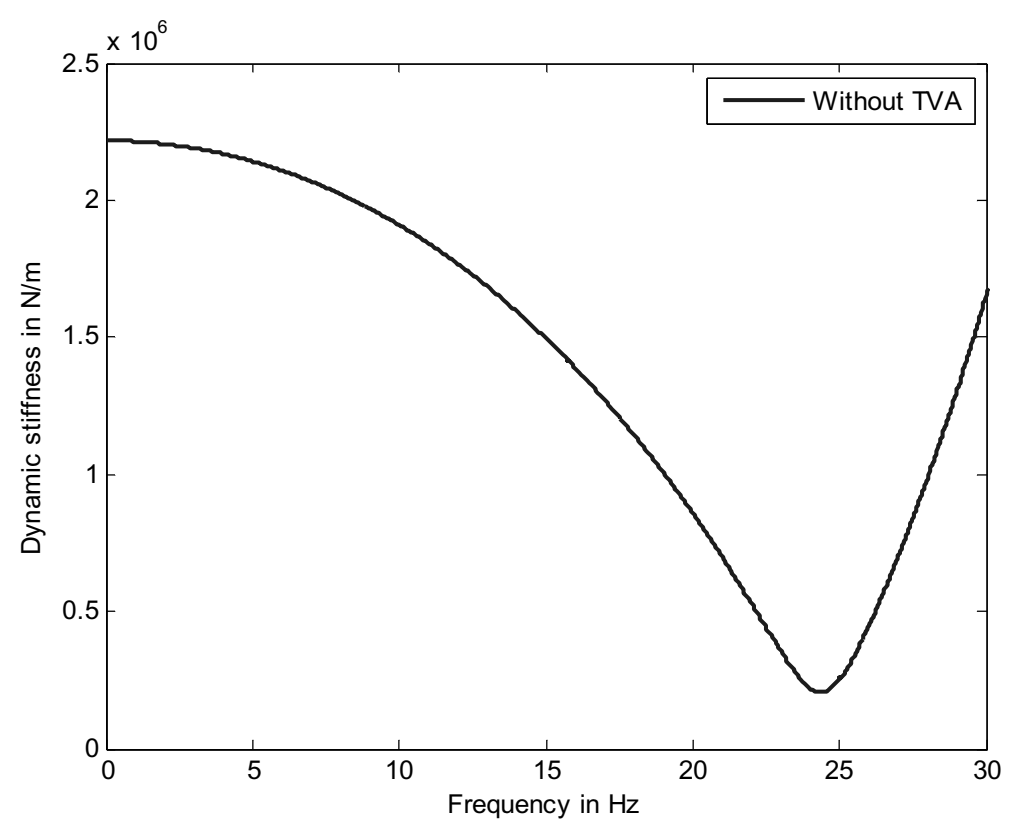

Fig. 8. Dynamic stiffness of a typical fluid mount (zoomed to notch) - Linear Plot.

\section{Passive fluid mount design of Fig. 4 (without the TVA)}

The dynamic stiffness of a passive fluid mount without a TVA was derived in Eq. (4) and is shown in Fig. 7. As it can be seen from Fig. 7, the dynamic stiffness of a typical passive fluid mount without a TVA has one notch and one peak. Figure 8 shows the linear plot of the dynamic stiffness versus frequency, zoomed to the notch frequency, and it can be seen that the notch frequency is about $25 \mathrm{~Hz}$. 


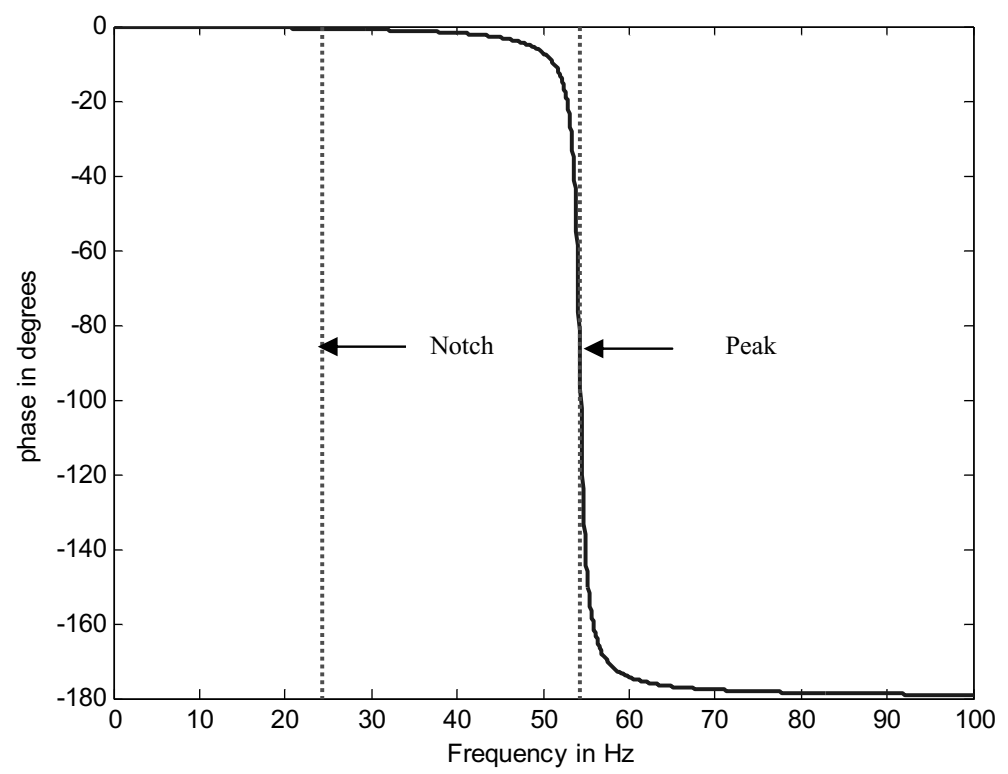

Fig. 9. Phase between input displacement and lower chamber piston displacement versus frequency.

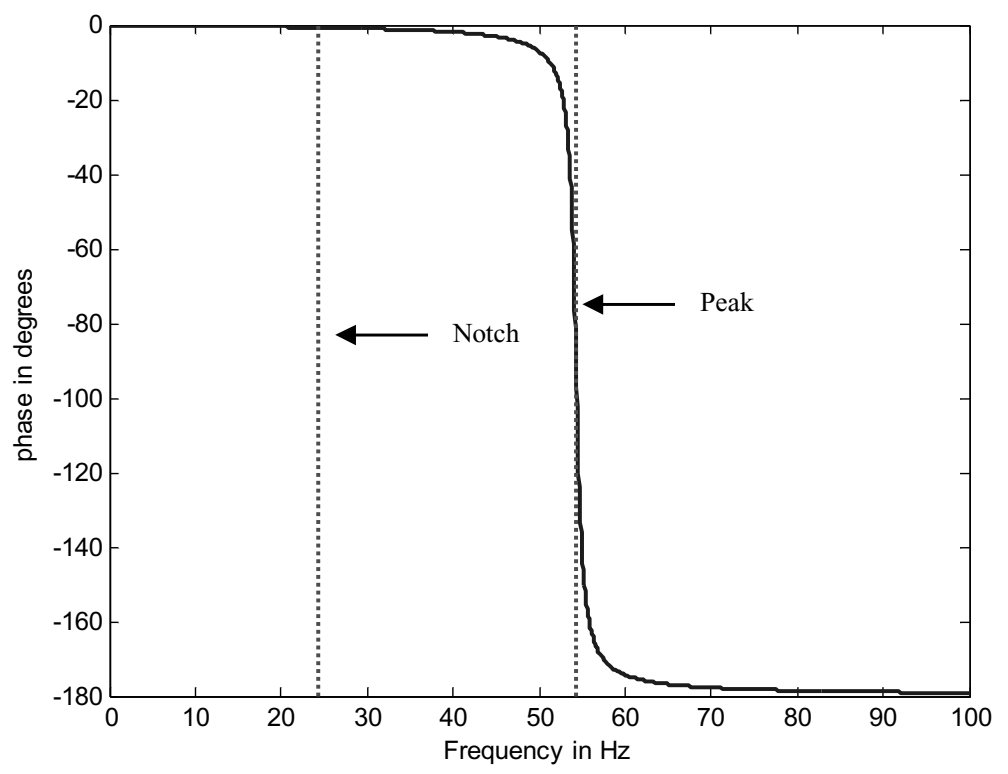

Fig. 10. Phase between flow rate through the inertia track and input flow rate versus frequency.

To explain why and under what conditions the notch and peak frequencies occur, the bottom fluid chamber piston displacement relative to the input displacement given to the fluid mount is studied. The fluid flow rate through the inertia track versus input flow rate is also studied. Figures 9 and 10 show the phase difference between the input and the bottom chamber piston displacements, and the phase difference between the flow rate through the inertia track and the input flow rate versus frequency; respectively. Figure 9 shows that at the notch frequency, the input and the piston displacements are in phase. Meaning, when compressive input displacement is applied to the top chamber, the top chamber is pressurized. At the notch frequency, the bottom chamber piston moves in phase with the input displacement; therefore, creating low pressure region in the bottom chamber, pulling the top chamber fluid downwards. So no fluid lock up takes place at the top chamber. But at the peak frequency, the input and piston 


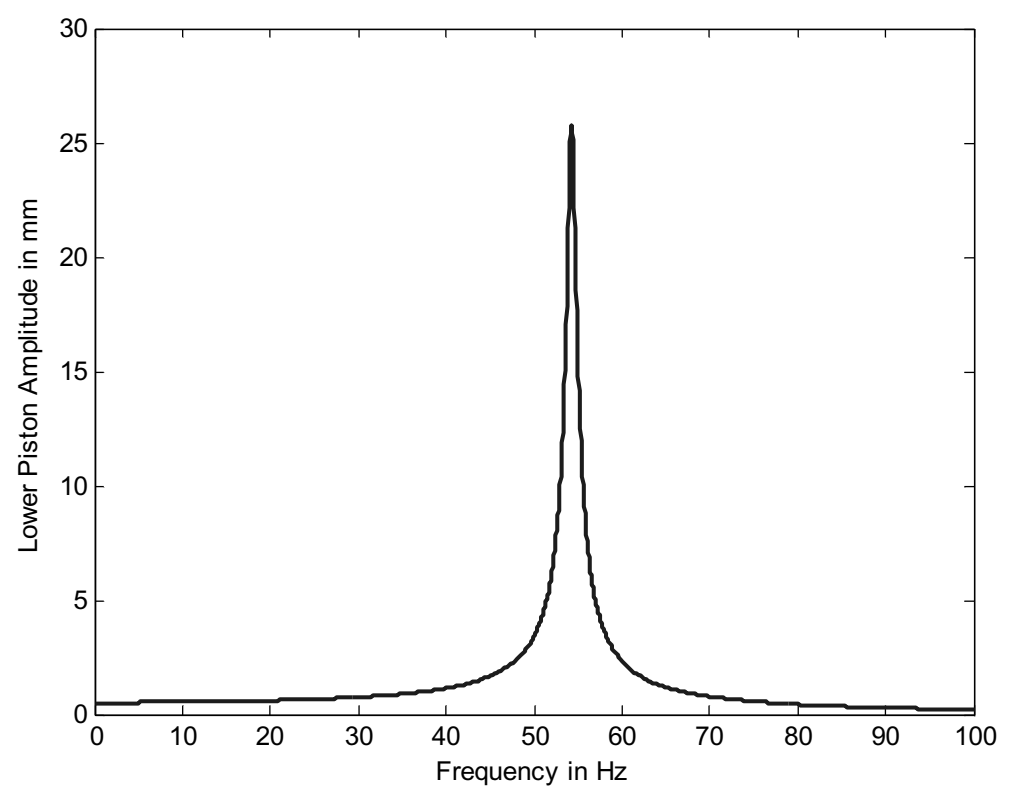

Fig. 11. Fluid mount without TVA - Amplitude of the piston versus frequency.

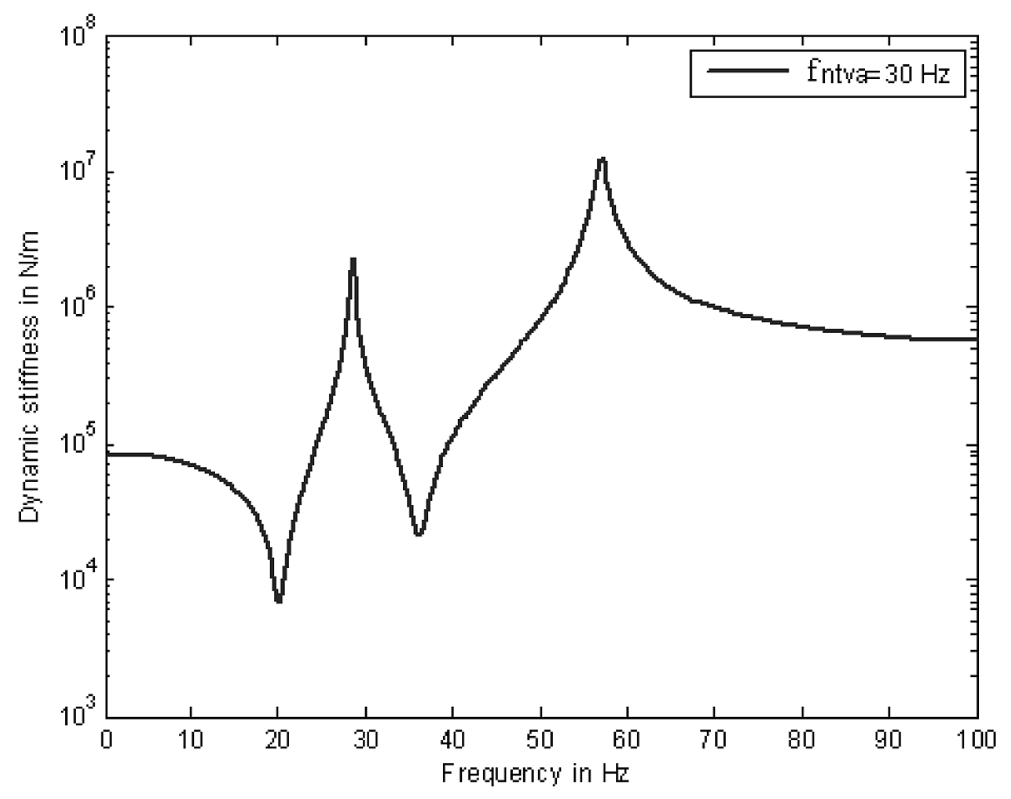

Fig. 12. Dynamic stiffness of a fluid mount plus TVA.

displacements are out of phase. At the peak frequency, the top chamber fluid can no longer flow to the bottom chamber since the piston in the bottom chamber is forcing fluid to the top chamber. The fluid is trapped in the top chamber and as a result the dynamic stiffness increases to a very high value at the peak frequency.

Figure 10 indicates the same conclusions. In order to make sure the design of Fig. 4 is practical, displacement of the bottom chamber piston needs to be monitored and make sure it is not too large.

With no TVA, piston displacement versus frequency is plotted in Fig. 11. Figure 11 indicates that the maximum displacement of the bottom chamber piston is $\pm 25 \mathrm{~mm}$ at the peak frequency, which is reasonable and acceptable. At all other frequencies, the piston displacement will be less than $\pm 25 \mathrm{~mm}$. 


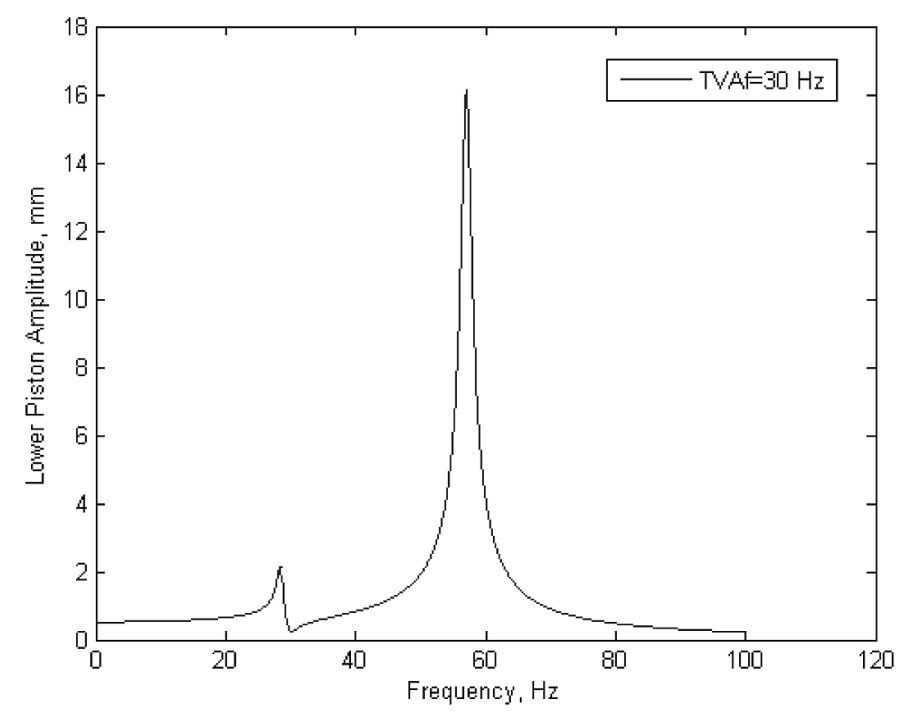

(a)

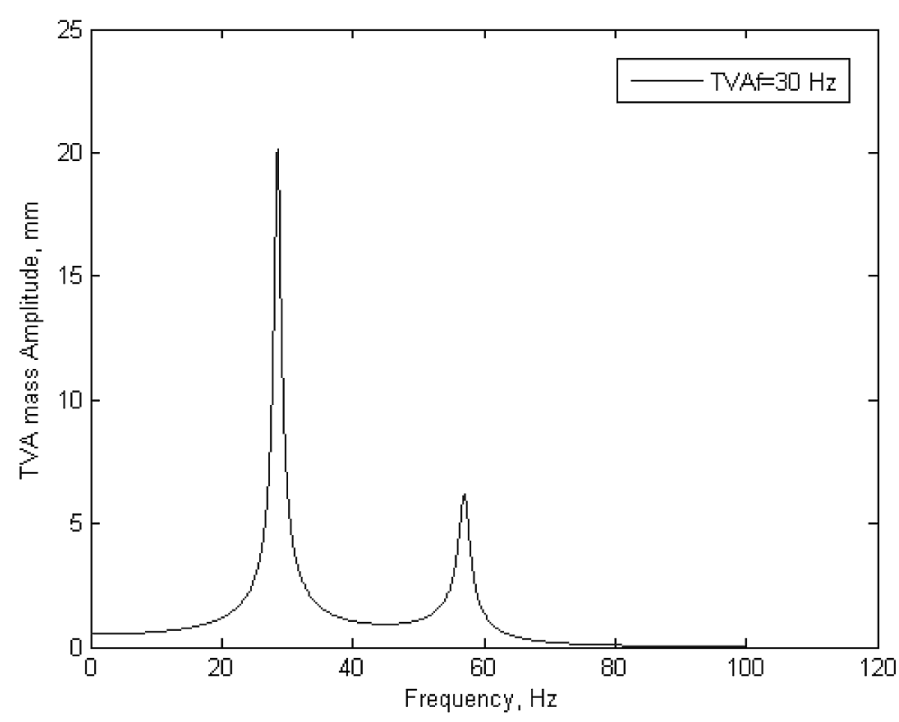

(b)

Fig. 13. Amplitude of the bottom chamber piston and amplitude of the TVA mass.

\section{Passive fluid mounts with a TVA}

If we now add a TVA to the bottom chamber piston, the design of Fig. 4 results. A typical dynamic stiffness of a fluid mount plus a TVA is shown in Fig. 12. It can be concluded that the dynamic stiffness versus frequency, corresponding to the fluid mount plus the TVA, has two notch frequencies while the typical passive fluid mount dynamic stiffness has only one notch frequency.

Before analyzing the effect of TVA parameters on the dynamic stiffness of the new fluid mount design, it is necessary to make sure that the vibration amplitudes of the bottom chamber piston and TVA mass are reasonable and practical. Figure 13 shows the displacement of the bottom chamber piston and the TVA mass; respectively.

As it can be concluded from Fig. 13, the maximum amplitude of the bottom chamber piston is less than $20 \mathrm{~mm}$ and the maximum amplitude of the TVA mass is around $20 \mathrm{~mm}$. These values show that the fluid mount plus TVA 
Table 2

TVA tuned to 10,20 and $30 \mathrm{~Hz}$ natural frequency

\begin{tabular}{ccc}
\hline $\mathrm{K}_{T V A}\left(\mathrm{~K}_{b 2}\right), \mathrm{N} / \mathrm{m}$ & $\mathrm{m}_{T V A}\left(\mathrm{M}_{b 2}\right), \mathrm{Kg}$ & $\mathrm{f}_{T V A}, \mathrm{~Hz}$ \\
\hline 394.8 & 0.1 & 10 \\
1579.1 & 0.1 & 20 \\
2467.4 & 0.1 & 25 \\
\hline \multicolumn{4}{c}{ Table 3} \\
TVA tuned to 30, 40 and 50 Hz natural frequency \\
\hline $\mathrm{K}_{T V A}\left(\mathrm{~K}_{b 2}\right), \mathrm{N} / \mathrm{m}$ & $\mathrm{m}_{T V A}\left(\mathrm{M}_{b 2}\right), \mathrm{Kg}$ & $\mathrm{f}_{T V A}, \mathrm{~Hz}$ \\
\hline 3553.1 & 0.1 & 30 \\
6316.5 & 0.1 & 40 \\
9869.6 & 0.1 & 50 \\
\hline
\end{tabular}

is good for applications with very low input displacement amplitudes such as aerospace applications. Note that $X_{i n}$ was assumed to be equal to $0.0381 \mathrm{~mm}[10]$.

\section{Parametric studies}

TVA is composed of 3 main parts: mass, stiffness and damping. The location and the depth of the new notch depend on the TVA's parameters. TVA, as an individual vibrating system, has its own natural frequency $\left(f_{t}\right)$. Fluid mount without the TVA has a notch frequency " $f_{n c}$ " and a peak frequency " $f_{\text {peak }}$ ". The natural frequency of the TVA could be placed below the fluid mount notch frequency, or in between the notch frequency $\left(f_{n c}\right)$ and the peak frequency $\left(f_{\text {peak }}\right)$, or above the peak frequency $\left(f_{\text {peak }}\right)$. So a parametric study will be conducted to see the effect of TVA on the dynamic stiffness of the fluid mount. TVA will be tuned such that it's natural frequency will be:

1. Below the fluid mount notch frequency, $f_{n c}$ (Region I)

2. Between $f_{n c}$ and $f_{\text {peak }}$ (Region II)

3. Or above the fluid mount peak frequency, $f_{\text {peak }}$ (Region III)

The TVA, in general, is made of a mass bonded to a rubber piece. So the TVA rubber will have stiffness and damping. The imaginary stiffness of the TVA, is expressed as follows:

$$
K^{\prime \prime}=\tan \delta \cdot K^{\prime}
$$

Where, $K^{\prime}$, is the elastic stiffness and, $\tan \delta$, represents the amount of damping in the rubber. So for a given elastomer (or a given $\tan \delta$ ) $K^{\prime \prime}$ is not controllable. So, only change in the stiffness and the mass of the TVA can be considered. From practical viewpoint, there are some space and weight constraints, so the range in which we can change the mass is somewhat limited. But the TVA stiffness can be varied widely.

\subsection{TVA effect on the dynamic stiffness of the fluid mount (Region 1)}

From Figs 7 and 8, we learnt that the notch frequency of the fluid mount without the TVA was about $25 \mathrm{~Hz}$ and its peak frequency was about $55 \mathrm{~Hz}$. From Fig. 12, we learnt that when the TVA is tuned to $30 \mathrm{~Hz}$, the notch of the TVA occurs below $30 \mathrm{~Hz}$. Thus for region 1, the natural frequency of the TVA will be held below $25 \mathrm{~Hz}$ and the TVA's natural frequency will be swept over region $1(0$ to $25 \mathrm{~Hz})$. The natural frequency of the TVA is calculated as follows.

$$
f_{n t v a}=\frac{1}{2 \pi} \sqrt{\frac{K_{b 2}}{M_{b 2}}}(H z)
$$

In the region 1, three different TVA natural frequencies are considered, 10, 20 and $25 \mathrm{~Hz}$. See Table 2.

When the TVA's natural frequency is tuned to be below the fluid mount's notch frequency (Region 1), the TVA's natural frequency has little effect on the fluid mount's peak frequency (see Fig. 14). When the TVA's natural frequency is kept far from the fluid mount's notch frequency, the fluid mount's notch does not move with the addition of the TVA, but once the TVA's natural frequency approaches the fluid mount's notch frequency, the fluid mount's notch frequency shifts higher. 


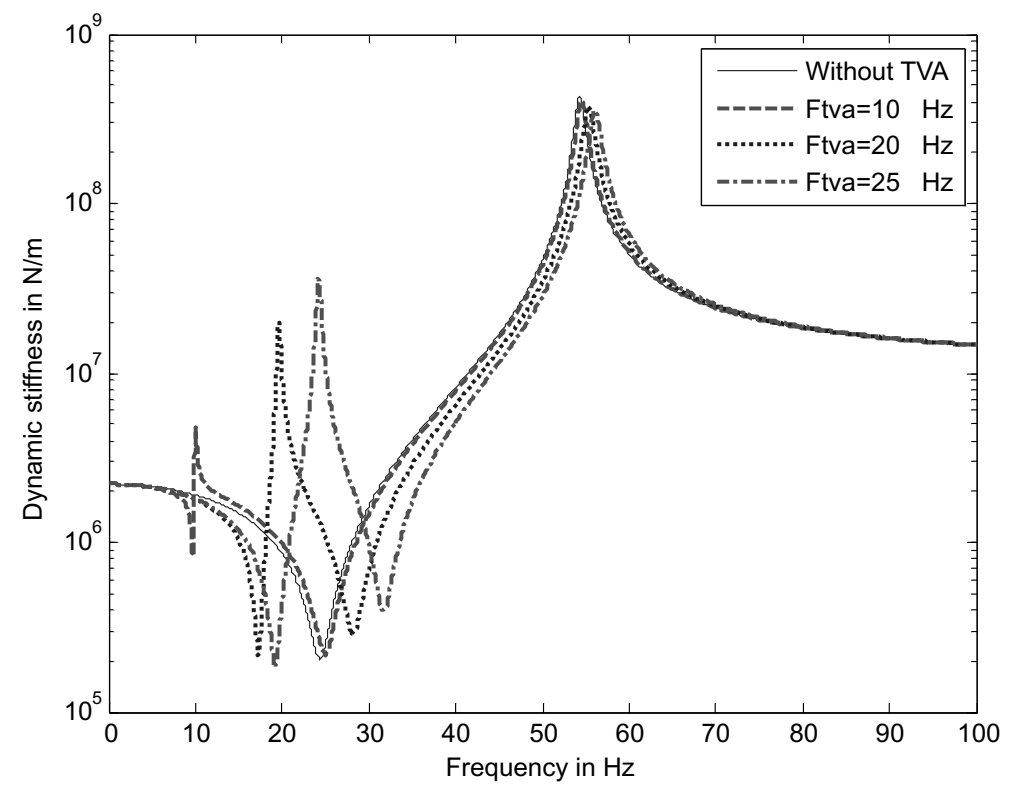

Fig. 14. Effect of the natural frequency of the TVA on the dynamic stiffness of the fluid mount plus TVA (Region 1).

\subsection{TVA effect on the dynamic stiffness of the fluid mount (Region 2)}

In order to study the effect of TVA on the dynamic stiffness of the fluid mount in region 2, the following TVA natural frequencies are considered. In the region 2, three different TVA natural frequencies are considered, 30, 40 and $50 \mathrm{~Hz}$. See Table 3.

The simulation results are shown in Fig. 15. Figure 15 indicates that as TVA is added in between the fluid mount notch and peak frequencies, it causes both the notch and the peak to shift. The addition of the TVA causes the fluid mount notch frequency to shift down and the peak frequency to shift up. It can be also seen from Fig. 15 that increasing the natural frequency of the TVA would decrease the notch depth. It means that at high frequencies, addition of a TVA to the fluid mount is not so effective. The decrease in the TVA notch is due to the hysteretic damping of the TVA rubber. The equivalent viscous damping of the TVA rubber is defined by Eq. (8):

$$
B b 2=\frac{\tan \delta K_{b 2}}{\omega_{n t v a}}
$$

Where $K_{b 2}$ is defined as:

$$
K_{b 2}=\omega_{n t v a}^{2} \times M_{b 1}
$$

Since we kept the TVA mass constant, an increase in TVA natural frequency implies an increase in stiffness $\mathrm{K}_{b 2}$. When TVA stiffness goes up, so does the equivalent viscous damping as shown by Eq. (8). So, at very high frequencies, the TVA's notch depth will decrease due to increase in rubber damping.

\subsection{TVA effect on the dynamic stiffness of the fluid mount (Region 3)}

In order to study the effect of TVA on the dynamic stiffness of the fluid mount in region 3, the following TVA natural frequencies are considered. In the region 3, three different TVA natural frequencies are considered, 60, 70 and $80 \mathrm{~Hz}$. See Table 4

The simulation results are shown in Fig. 16. Figure 16 illustrates that when the TVA's natural frequency is above the peak frequency of the fluid mount, the TVA has little impact on the fluid mount notch. There is a slight shift in the fluid mount's notch frequency but that is due to the overall mass of the piston increasing by hanging a TVA on 
Table 4

TVA tuned to 60,70 and $80 \mathrm{~Hz}$ natural frequency

\begin{tabular}{ccc}
\hline $\mathrm{K}_{T V A}\left(\mathrm{~K}_{b 2}\right), \mathrm{N} / \mathrm{m}$ & $\mathrm{m}_{T V A}\left(\mathrm{M}_{b 2}\right), \mathrm{Kg}$ & $\mathrm{f}_{T V A}, \mathrm{~Hz}$ \\
\hline 14,212 & 0.1 & 60 \\
19,344 & 0.1 & 70 \\
25,266 & 0.1 & 80 \\
\hline
\end{tabular}

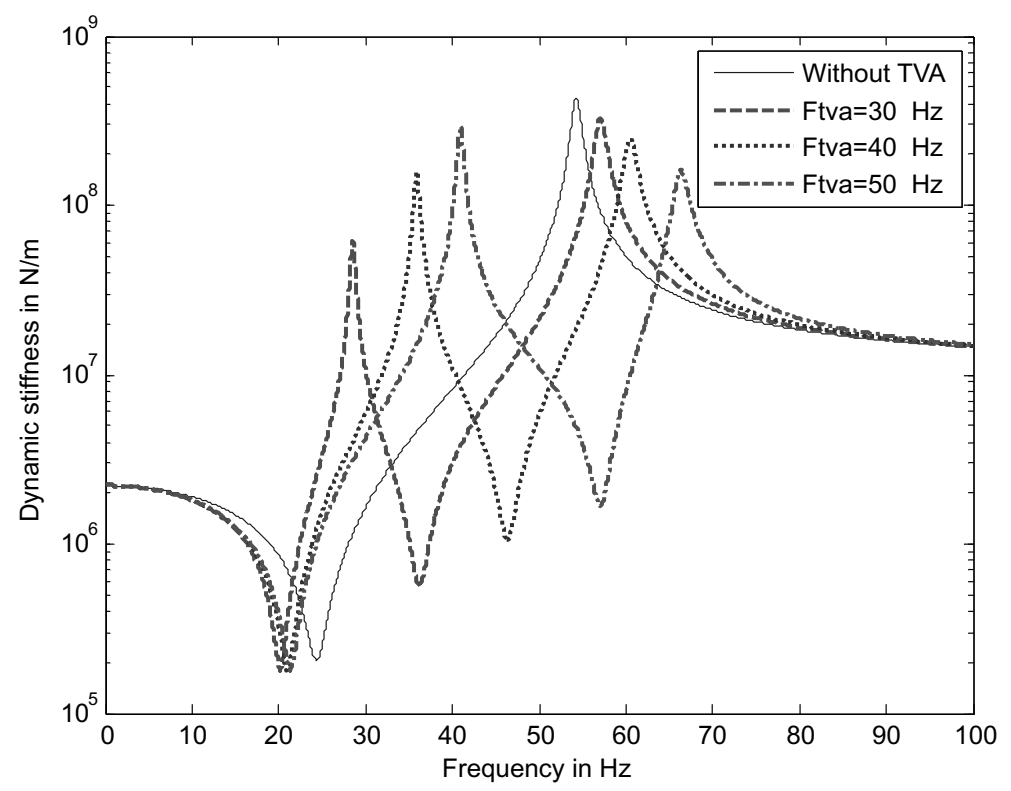

Fig. 15. Effect of the natural frequency of the TVA on the dynamic stiffness of the fluid mount plus TVA (Region 2).

it. There is also a shift in the fluid mount's peak frequency and that is also due to the overall increase in the piston mass.

It can be seen from Fig. 16 that adding a TVA to a fluid mount at high frequencies is not very effective since the TVA's notch depth is not deep. This is again due to equivalent viscous damping being high at high frequencies.

\subsection{Overall effect}

In order to compare the effect of a TVA on the dynamic stiffness of a fluid mount in all the three regions (Regions 1,2 and 3), Fig. 17 is plotted.

It can be concluded from Fig. 17 that an increase in the natural frequency of the TVA will result in an increase in the location of the new notch frequency. Additionally, the deepest TVA notch can be achieved when the natural frequency of the TVA is closest to the notch frequency of the fluid mount.

\section{Semi-active mount}

It is worth mentioning that the TVA fluid mount system that was studied in this paper was a passive device. Figures 14, 15 and 16 showed that changing the stiffness of the TVA changes the location of the new notch. It means if a variable stiffness semi-active TVA is used, the location of the new notch can be controlled semi actively. 


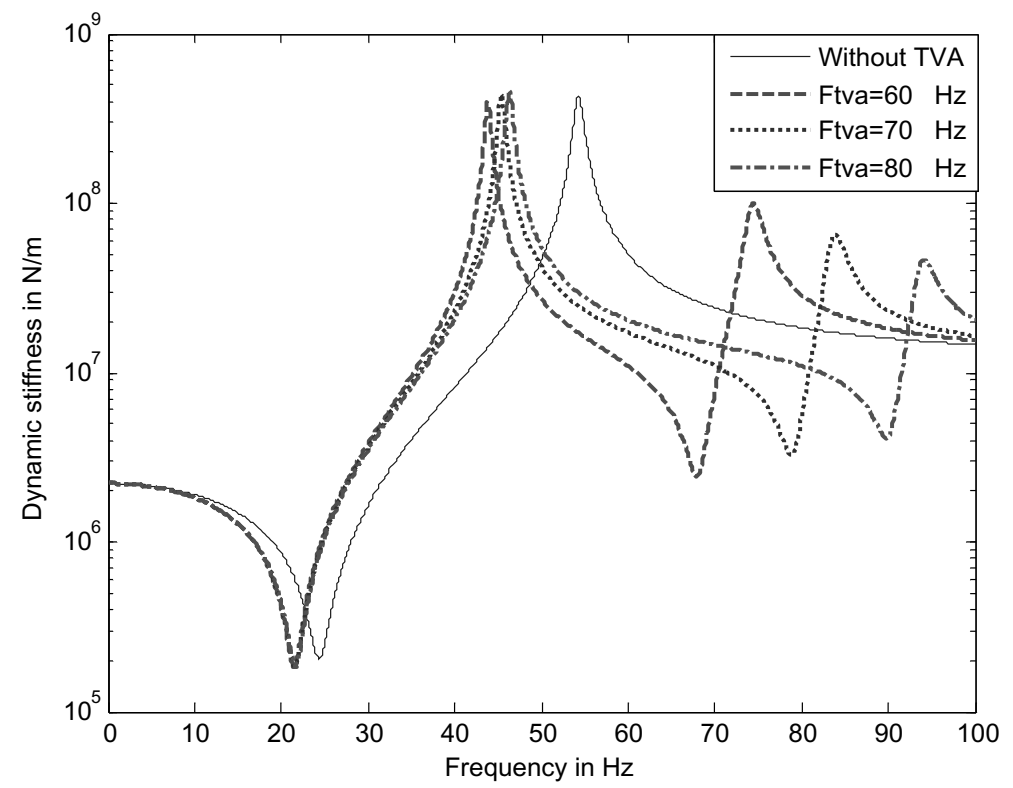

Fig. 16. Effect of the natural frequency of the TVA on the dynamic stiffness of the fluid mount plus TVA (Region 3).

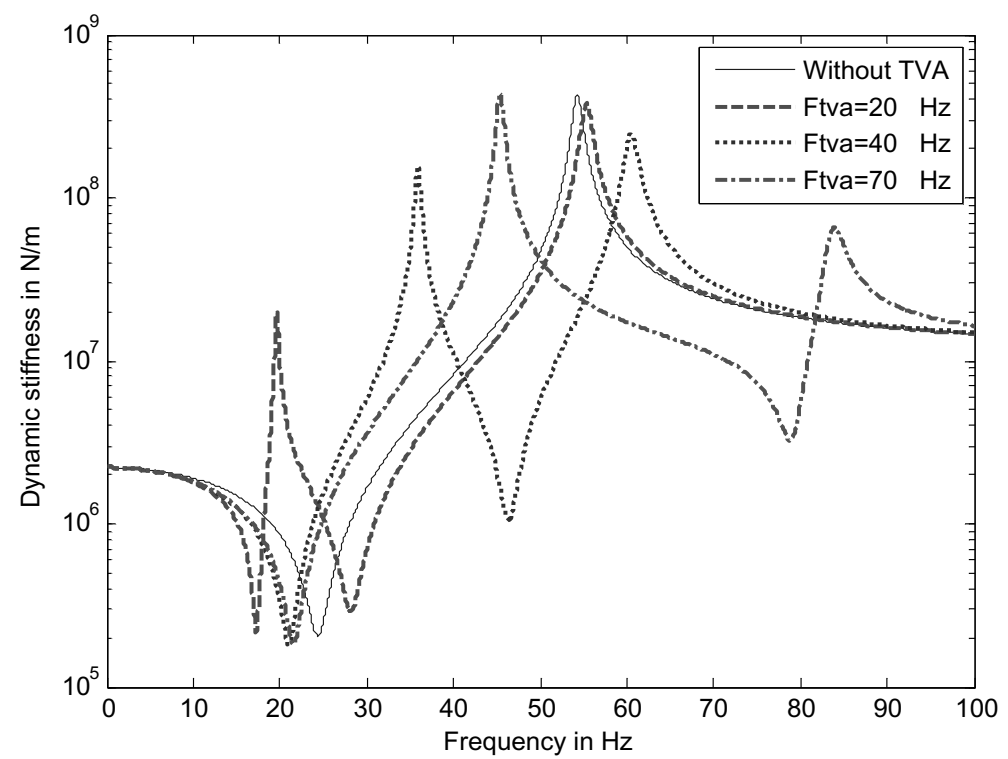

Fig. 17. Effect of the natural frequency of the TVA on the dynamic stiffness of the fluid mount plus TVA (Overall).

\section{TVA design}

In the parametric study section, the effect of a TVA on the dynamic stiffness of a fluid mount was studied. In practice, the location of the desired notch frequencies will be known and the designer's task is to find a set of fluid mount and TVA parameters that will result in the ideal notch locations.

For example suppose that we need to design a fluid mount plus a TVA for an aircraft engine and we need to place the first notch at $25 \mathrm{~Hz}$ and the second notch at $50 \mathrm{~Hz}$. As far as fluid mount is concerned, let's assume the same fluid mount parameters, as given in Table 1, are used and the fluid mount notch frequency is at $25 \mathrm{~Hz}$. So, the TVA is now used to create the $50 \mathrm{~Hz}$ notch. 
Table 5

Different sets of Fluid mount plus TVA parameters for $\omega_{1}=25 \mathrm{~Hz}$ and $\omega_{2}=50 \mathrm{~Hz}$

\begin{tabular}{|c|c|c|c|c|c|c|c|c|c|c|c|}
\hline \multirow[t]{2}{*}{$\begin{array}{l}K_{s t} \\
\mathrm{~N} / \mathrm{m}\end{array}$} & \multirow[t]{2}{*}{$\begin{array}{c}M_{t v a} \\
\text { grams }\end{array}$} & \multirow[t]{2}{*}{$\begin{array}{c}K_{t v a} \\
\mathrm{~N} / \mathrm{m}\end{array}$} & \multirow[t]{2}{*}{$\begin{array}{l}K_{b 1} \\
\mathrm{~N} / \mathrm{m}\end{array}$} & \multirow[t]{2}{*}{$\begin{array}{c}\omega_{t} \\
\mathrm{rad} / \mathrm{s}\end{array}$} & \multirow[t]{2}{*}{$\begin{array}{c}B_{b 2} \\
\text { N.s/m }\end{array}$} & \multirow[t]{2}{*}{$\begin{array}{l}\text { Notch depth } \\
\left(\text { for } \omega_{1}\right) \mathrm{N} / \mathrm{m}\end{array}$} & \multirow[t]{2}{*}{$\begin{array}{l}\text { Notch depth } \\
\left(\text { for } \omega_{2}\right) \mathrm{N} / \mathrm{m}\end{array}$} & \multicolumn{2}{|c|}{$\begin{array}{l}\text { Peak Piston Amplitude } \\
\quad\left(\text { for } \omega_{1}\right) \mathrm{mm}\end{array}$} & \multicolumn{2}{|c|}{$\begin{array}{l}\text { Peak TVA mass Amplitude } \\
\left.\text { (for } \omega_{2}\right) \mathrm{mm}\end{array}$} \\
\hline & & & & & & & & Peak 1 & Peak 2 & Peak 1 & Peak 2 \\
\hline $2.9276 \mathrm{e} 6$ & 100 & $7.3 \mathrm{e} 3$ & 5000 & 43 & 0.5404 & $2.7115 \mathrm{e} 6$ & $2.9276 \mathrm{e} 6$ & 9.7659 & 13.33 & 46.41 & 11.19 \\
\hline $3.232 \mathrm{e} 6$ & 150 & $9.475 \mathrm{e} 3$ & 7000 & 40 & 0.754 & $3.0109 \mathrm{e} 6$ & $3.232 \mathrm{e} 6$ & 9.2959 & 12.7038 & 41.49 & 7.5725 \\
\hline $3.54 \mathrm{e} 6$ & 200 & $1.08 \mathrm{e} 4$ & 9000 & 37 & 0.9299 & $3.2858 \mathrm{e} 6$ & $3.54 \mathrm{e} 6$ & 8.458 & 12.42 & 37.9 & 5.53 \\
\hline $4.021 \mathrm{e} 6$ & 250 & $1.141 \mathrm{e} 4$ & 13000 & 34 & 1.0367 & $3.7615 \mathrm{e} 6$ & $4.021 \mathrm{e} 6$ & 6.3622 & 12.63 & 32.7 & 3.93 \\
\hline
\end{tabular}

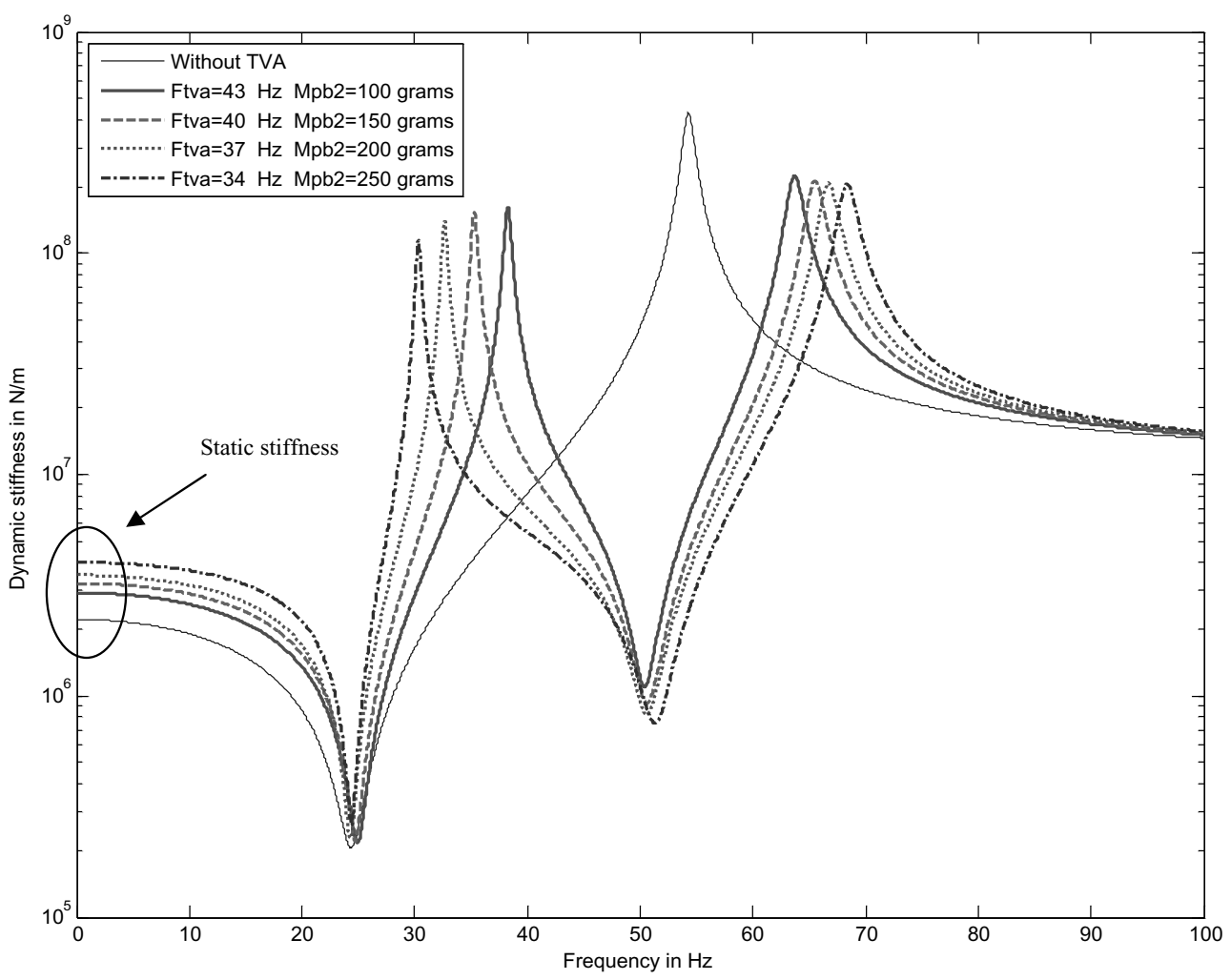

Fig. 18. Dynamic stiffness of the fluid mount plus TVA corresponding to set of parameters of Table 1.

Different sets of TVA parameters can result in a $50 \mathrm{~Hz}$ notch. The natural frequency of a TVA depends on the TVA's stiffness and mass. So to create a $50 \mathrm{~Hz}$ notch, one can choose many different TVA stiffness and mass combinations. For instance, four different sets of TVA parameters are given in Table 5. In this table, the TVA's mass is increased and the TVA's stiffness is also increased to maintain a $50 \mathrm{~Hz}$ notch.

The dynamic stiffness of the fluid mount plus the TVA, for different sets of TVA parameters presented in Table 5, is shown in Fig. 18. Figure 18 illustrates that a wider $50 \mathrm{~Hz}$ notch can be achieved when the TVA mass is larger. Notice that as TVA mass goes up, the $2^{\text {nd }}$ notch gets wider but it results in narrowing the fluid mount notch.

Notice that as the TVA mass increases, the static stiffness of the fluid mount/TVA system increases. Heavier the TVA mass is, heavier the overall piston mass will be; therefore, larger input force will be required to move the piston.

Figure 18 illustrates that in general, a larger TVA mass is better than a smaller TVA mass as long as an increase in the TVA mass does not impact the fluid mount's notch width, and the lower chamber piston and TVA mass dynamic displacements. 


\section{Conclusions}

In this paper, a new single pumper fluid mount design was introduced where the bottom chamber rubber diaphragm was replaced with a piston, a fabric diaphragm, and a rubber spring. A tuned vibration absorber (TVA) was added onto the piston. It was shown that an addition of a TVA to the fluid mount resulted in two notch frequencies. Having two notch frequencies result in better cabin noise and vibration isolation than having one, and the location of the new notch is easily controllable and directly dependent on the TVA's natural frequency.

It is important to mention that the addition of the TVA to the piston, exhibits two notches but it also exhibits two peak frequencies. It will be problematic if the engine operational frequency lands at the peak frequencies. Fluid mounts with one notch and one peak frequencies, are effectively used in the industry despite its high dynamic stiffness at the peak frequency, so, even though the new proposed design has two peaks, it can still be effectively utilized as long as the peak frequencies are avoided or the engine RPM is only coincident with the peak frequencies for only a short period of time. Since with existing fluid mounts, the peak frequency has not been an issue, the two new peaks will not be as well an issue with this new design.

Simulation results indicated that in order to keep the piston and the TVA motion reasonable, the proposed fluid mount design is more suitable for aerospace applications than the automotive applications since in the aerospace applications, the engine input motions are smaller.

If the proposed design is used in the aerospace applications, one of the notches can be tuned to coincide with the $\mathrm{N} 1$ frequency (engine low speed shaft imbalance frequency) and the other notch can be tuned to coincide with the $\mathrm{N} 2$ frequency (engine high speed shaft imbalance frequency) at the cruise speed. With this new design, better cabin noise and vibration reduction can be achieved as compared with current fluid mount designs since two disturbance inputs are isolated rather than one.

Simulation results indicated that, addition of a TVA to the fluid mount is most effective at low frequencies rather than high frequencies. Figure 18 illustrated that in general, a larger TVA mass is better than a smaller TVA mass as long as an increase in the TVA mass does not impact the fluid mount's notch width, and the motions of the lower chamber piston and the TVA mass.

\section{References}

[1] M.S. Foumani, A. Khajepour and M. Durali, Optimization of Engine Mount Characteristics Using Experimental/Numerical Analysis, Journal of Vibration and Control pp. 1121-1139. 20032001.

[2] Y.H. Yu, N.G. Naganathan and R.V. Dukkipati, A literature review of automotive vehicle engine mounting systems, Mechanism and Machine Theory 36 (Jan 2001), 123-142.

[3] W.C. Flower, Understanding hydraulic mounts for improved vehicle noise, vibration and ride qualities, SAE Transactions 94 (1985), $832-841$.

[4] N. Vahdati, A detailed mechanical model of a double pumper fluid mount, Journal of Vibration and Acoustics 120 (1998), 361-370.

[5] N. Vahdati, Double-notch single-pumper fluid mounts, Journal of Sound and Vibration 285 (Jul 2005), 697-710.

[6] W.B. Shangguan and Z.H. Lu, Experimental study and simulation of a hydraulic engine mount with fully coupled fluid-structure interaction finite element analysis model, Computers \& Structures 82 (Sep 2004), 1751-1771.

[7] Y.K. Ahn, Y.C. Kim, B.S. Yang, M. Ahmadian, K.K. Ahn and S. Morishita, Optimal design of an engine mount using an enhanced genetic algorithm with simplex method, Vehicle System Dynamics 43 (Jan 2005), 57-81.

[8] N. Vahdati and M. Ahmadian, Variable volumetric stiffness fluid mount design, Shock and Vibration 11 (2004), 21-32.

[9] R.C. Rosenberg and D.C. Karnopp, Introduction to Physical System Dynamics, McGraw-Hill Book Company, 1983.

[10] Gordon J. Hookey, Powerplants Group Chairman's Factual Report, National Transportation Safety Board Office of Aviation Safety, NTSB ID No. DCA99MA060, Sept 30, 1999, AA1420_8A.pdf. 

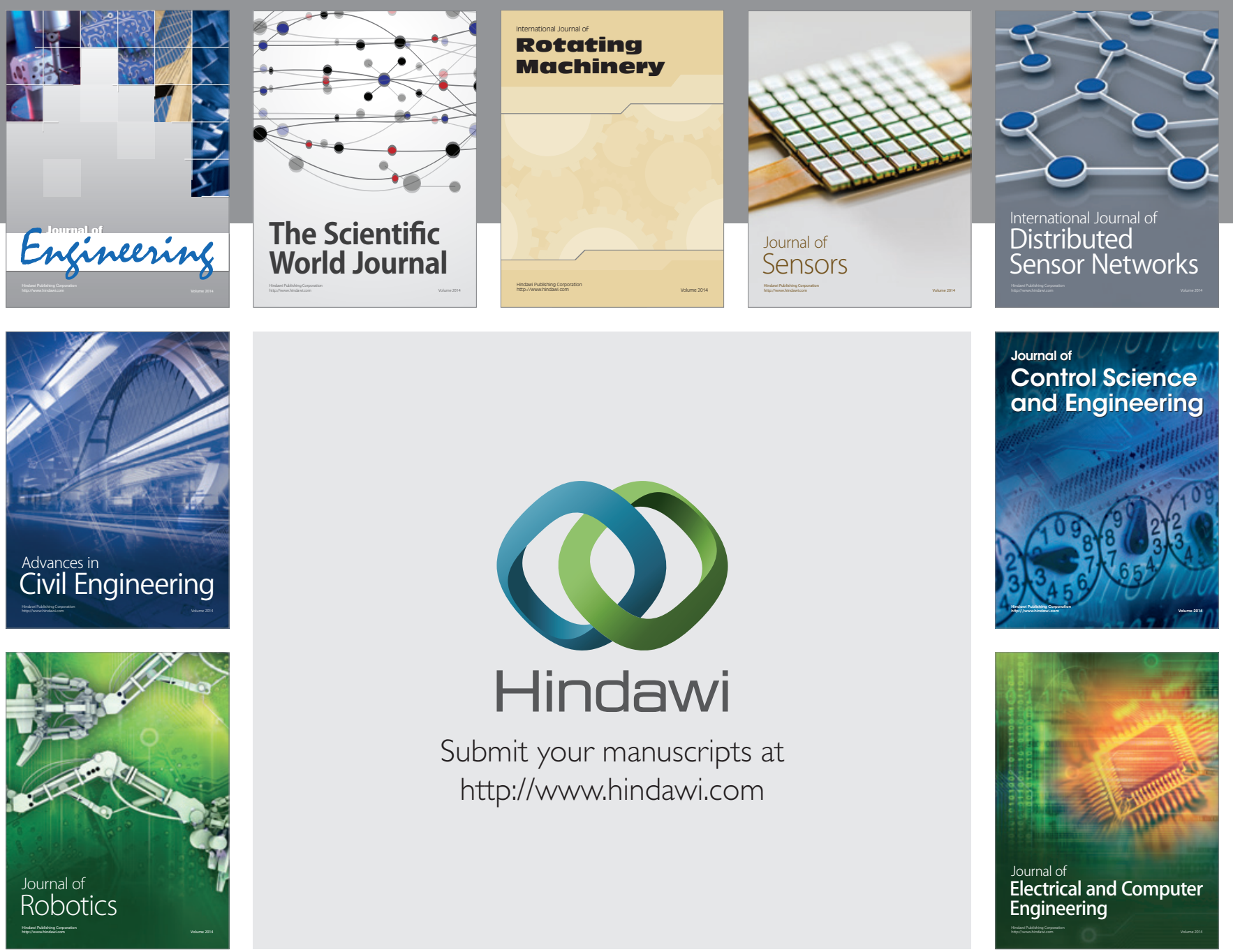

Submit your manuscripts at

http://www.hindawi.com
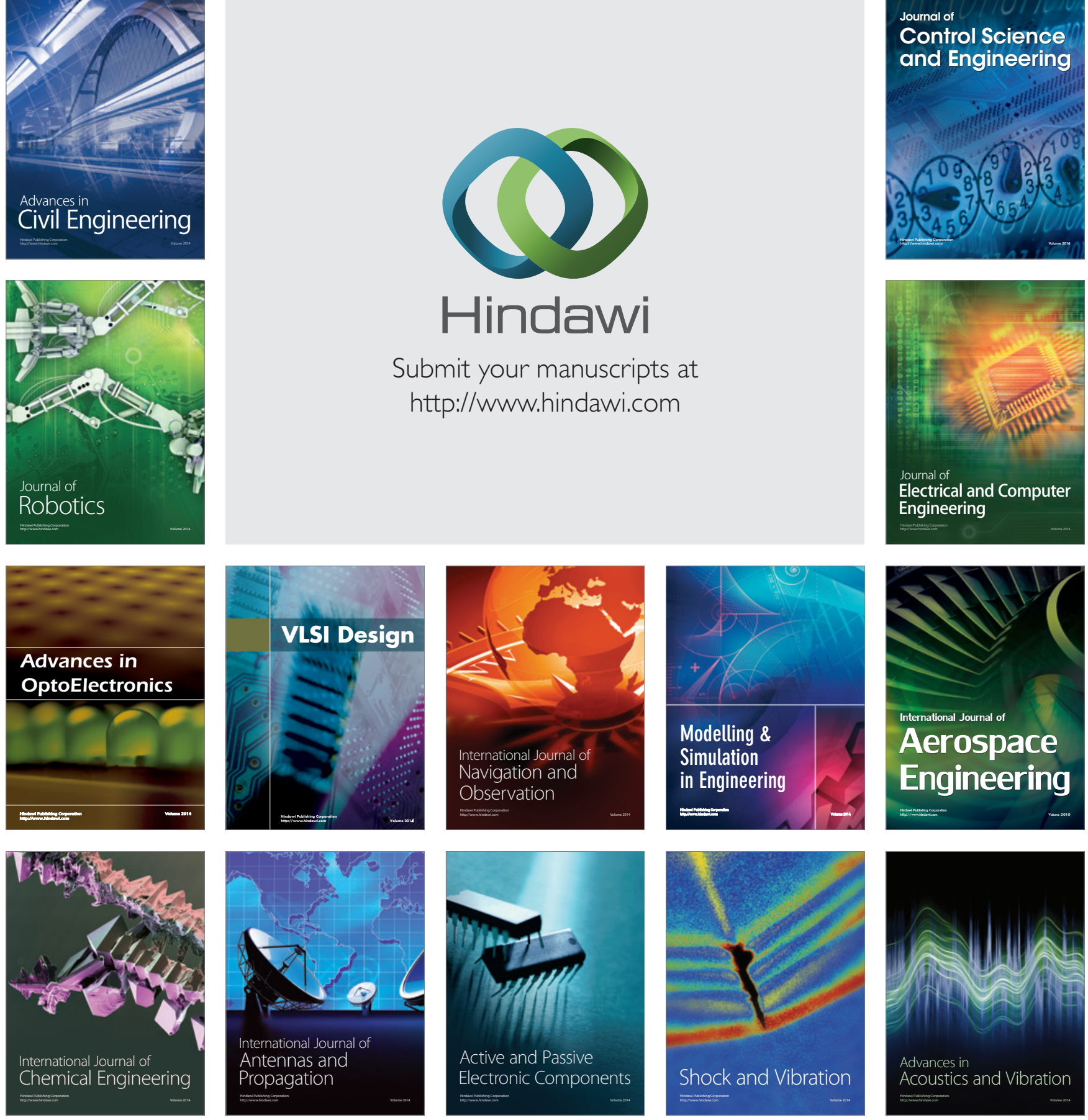